\title{
A FERRITE POTENTIAL INFLUENCE ON HEAT TRANSFER CONDITIONS IN INDUSTRIAL MOLD DURING THE CONTINUOUS CASTING OF STEELS
}

\begin{abstract}
V. Karlinski ${ }^{a}$,
W. Fogazzi ${ }^{\text {, }}$

B. V. de Souza',

C. R. F. Ferreira ${ }^{d}$,

C. A. dos Santos ${ }^{\mathrm{e}}$, and J. A. Spim

${ }^{\text {f }}$ Universidade Federal do Rio Grande do Sul Centro de Tecnologia/LAFUN Bairro Agronomia

CP. 15.021, Porto Alegre, RS, Brasil

This paper aims to apply a solidification mathematical model to the process of the continuous casting of steel. Heat transfer coefficients in the mold were determined by the inverse method and they are related with both macrostructure conditions and carbon equivalents of carbon steels from peritectic reactions. Both structure characterization and ferrite potential were established by solidification parameters and chemical composition after casting. Samples were cut at different positions of the metal/mold interface, whereas the selected sections were polished and etched with a reagent for the metallographic examination. The image processing system was used to analyze as-cast structure for every selected position. It was observed that during casting, numerical predictions about metal/mold heat transfer coefficients along the mold are in accordance with type-A and B steels ferrite potential, due to both its sticking and depression tendency.
\end{abstract} spim@ufrgs.br

\section{NOMENCLATURE}

Cp equivalent carbon

Cr' equivalent chromium

dist distance

FP ferrite potential

h heat transfer coefficient, $\mathrm{W} / \mathrm{m}^{2} \mathrm{~K}$

L liquid

MDF finite difference method

Ni’ equivalent nickel

$\mathrm{T}$ temperature, $\mathrm{K}$

Tp thermocouple

Greek symbols

$\delta \quad$ delta ferrite

$\gamma \quad$ austenite

\section{Subscripts \\ i initial value \\ $\mathrm{m} / \mathrm{m}$ metal/molde \\ n limit value \\ sim simulated \\ exp experimental}

\section{INTRODUCTION}

The occurrence of heat transfer during primary (metal/mold), secondary (sprays zones) and tertiary (free radiation) cooling stages is the main phenomenon concerned with the continuous casting of steels. Either the thermal behavior prediction or determination of such heat transfer systems becomes important as it directly interferes in solidification,
Keywords: ferrite potential, solidification, continuous casting, mathematical model. especially during the initial stage of the solid shell formation inside the mold.

In order to understand the mold behavior, it is important to know how the heat transfer from the metal to the cooling fluid occurs. For a heat transfer global analysis, the relative influence of every active heat transfer way must be initially analyzed. In this stage, both liquid and solid metal, lubricant, physical space or air gap formed in the metal/mold interface, as well as the mold wall and the cooling fluid are considered as sources of thermal change. The solid metal layer formed along the mold works as an increasing barrier, which stems the heat flow, that is, it constitutes a thermal resistance that relatively increases the influence of the solid layer thermal conduction on the heat global fluid. The mold walls, however, do not represent an important thermal resistance to the heat conduction in the system, because, besides the order of magnitude of the walls thickness, mold materials, usually copper and its alloys, have a great capacity of transferring heat due to their high thermal diffusibility.

For the thermal contact between both metal and mold, three regions of contact can be observed: one from the meniscus up to the initial point of solidification, where the liquid metal is separated from the mold by a layer of mold powder; the second one has a good thermal contact between the solid metal and the mold wall, due to the ferrostatic pressure on the solidified layer by the liquid metal. Furthermore, its behavior has an important influence on superficial quality of the ingot. In the third one, there is either a physical separation or a well-defined air gap formation between both metal and mold, making difficult the heat flow. This separation can vary according to the steel chemical composition and 
its ferrite potential, which represents a sticking or depression tendency, as shown by (Brimacombe, 1973; Brimacombe et al., 1984; Mahapatra et al., 1991; Mills et al., 1991; Chandra et al., 1993).

The aim of this paper is to apply a numerical simulation model of solidification to a continuous casting of steels. This model is capable of predicting the heat transfer coefficient (h) evolution along the metal/mold interface, in different faces of a square 150 x $150 \mathrm{~mm}$ section mold according to the sticking or depression tendency presented by different types of steels. The results are compared with the macrostructure obtained from ingots by monitored heat, during the process of solidification.

\section{THEORY}

\section{Heat Transfer in the Mold}

The problem concerning about the metal/mold interfacial heat transfer has been of great interest of studying by researchers, due to its important influence on either the rate or speed of solidification. Several works have been developed aiming at characterizing the physical mechanism of heat transfer between both metal and mold contact interfaces, as it is shown by (Hills, 1969; Grill and Brimacombe, 1976; Lait et al., 1974; Lait and Brimacombe, 1984; Krishnan and Sharma, 1996; Santos et al., 2001).

In this work, the model by Barcellos et al. (2006) is employed to determine heat transfer coefficients (h) along the metal/mold interface. This method involves the measure of experimental temperatures obtained by thermocouples placed in the metal and/or mold in known positions. Those temperatures are compared to profiles of simulated ones by a numerical model of both solidification and heat transfer, previously examined. The procedure used to determine $h$ is performed by adopting an initial value of $h\left(h_{i}\right)$, by which, temperatures of each position in a numerical mesh, are calculated by a mathematical model for both mold and metal at different time intervals. Every interaction, the $h_{i}$ correction is carried out with either increasing or decreasing of a $\Delta \mathrm{h}_{\mathrm{i}}$ value and therefore, new temperatures are estimated.

\section{Optimization Strategy for Searching the Heat Transfer Coefficient along the Mold}

Search routines for determining heat transfer coefficients in the metal/mold interface $\left(\mathrm{h}_{\mathrm{m} / \mathrm{m}}\right)$, along the mold length, were developed by optimization strategies for increasing both the processing speed and the results accuracy obtained from the mathematical model of solidification. Figure 1 shows the flow-chart of the optimization algorithm for determining heat transfer coefficients in the metal/mold interface.
The routine acts interactively. Initially, the mesh determines a temperature profile of both metal and mold in the meniscus region, and it also compares the simulated temperature with the experimental one in the monitored point from a convenient initial value of $\mathrm{h}_{\mathrm{m} / \mathrm{m}}$.

Compared temperatures within the range of $\pm 1^{\circ} \mathrm{C}$ are accepted. The test is carried out when the numerical mesh moves from the meniscus region to the next monitored point.

At this time, the $h_{m / m}$ representativeness is verified by analyzing whether or not the simulated temperature is within the tolerable range. If necessary, the system can either increase or decrease the $h_{i}$ value and also repeat calculations from the previous monitored point with a new $h_{i}$ value. In each stage, the processing follows up to the distance of the next thermocouple, and successively, along the mold.

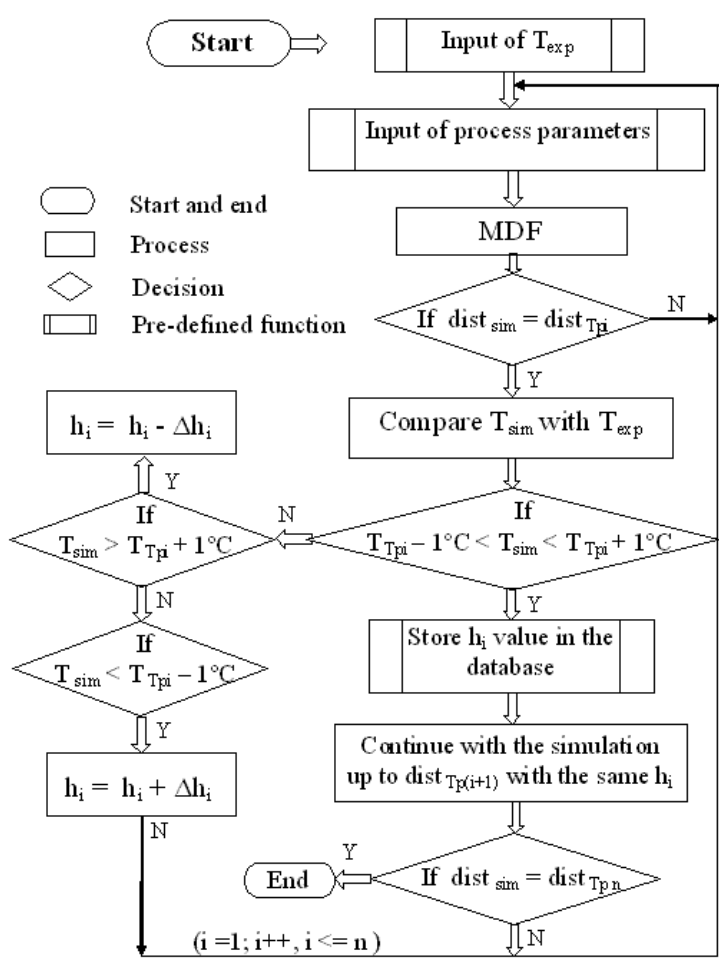

Figure 1. Flow-chart of the optimization algorithm for determining heat transfer coefficients in the metal/mold interface.

\section{Peritectic Reaction}

Solidification of steels starts with either $\delta$ ferrite or $\gamma$-austenite precipitation. In the case of carbon steels, the peritectic reaction $\mathrm{L}+\delta \rightarrow \gamma$ occurs with a $\mathrm{C}$ concentration rate between 0.09 and 0.53 in weight \%. Its effectiveness can be obtained by adding elements such as $\mathrm{C}, \mathrm{N}, \mathrm{Ni}, \mathrm{Mn}, \mathrm{Cu}$, responsible for austenite formation. Due to the difference of thermo-physical properties between $\gamma$ austenite and $\delta$-ferrite, this reaction originates 
undesirable phenomena such as stress, volumetric variation, segregation and inclusions precipitation, according to Matsuura et al. (1995). Figure 2 schematically shows the peritectic reaction, where $\delta$ ferrite, firstly formed, is encapsulated by $\gamma$-austenite from the $L+\delta$ reaction.
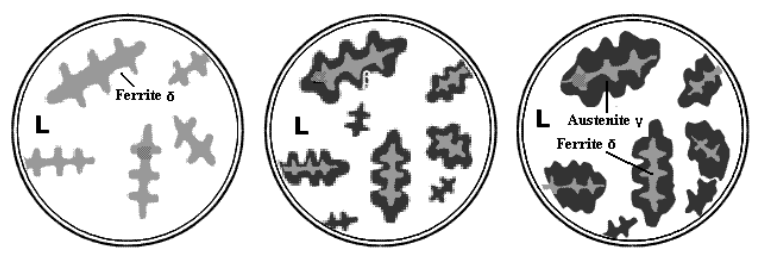

Figure 2. Schematic drawing of the peritectic reaction, showing $\delta$-ferrite encapsulation by $\gamma$ austenite.

In general, the effect of alloying elements is described by means of equivalent concentrations. For either carbon or low-alloy steels, the effect of alloying elements can be expressed by equivalent carbon, as follows:

$$
\begin{aligned}
& \mathrm{Cp}=[\% \mathrm{C}]+0,02 .[\% \mathrm{Mn}]+0,04 .[\% \mathrm{Ni}]-0,1 .[\% \mathrm{Si}] \\
& -0,04 .[\% \mathrm{Cr}]-0,1 .[\% \mathrm{Mo}]
\end{aligned}
$$

The equation was applied to 12 steels and compared with the ferrite fraction - or Ferrite Potential (FP) - obtained from solidification in experiments of differential thermo-analysis (Wolf and Kurz, 1981). This concept outlines a steel tendency to either shrink or expand during solidification inside the mold. For either carbon or low-alloy steels, the ferrite potential is defined as:

$$
\mathrm{FP}=2,5\left(0,5-\% \mathrm{C}_{\mathrm{P}}\right)
$$

For steels with a tendency to form depressions (type-A steels), FP values range between 0.85 and 1.05 , whereas for those with a tendency to stick to the mold wall (type B steels), these values are $\mathrm{FP}>1.05$ or $\mathrm{FP}<0.85$.

To calculate the ferrite potential for stainless steels, the presence of both equivalent chromium and nickel is taken into account, as follows:

$$
\begin{aligned}
& \mathrm{Cr}^{\prime}=[\% \mathrm{Cr}]+1,5[\% \mathrm{Cr}]+1,38[\% \mathrm{Mo}]+2[\% \mathrm{Nb}] \\
& +[\% \mathrm{Ti}] \\
& \mathrm{Ni}=[\% \mathrm{Ni}]+0,31[\% \mathrm{Mn}]+22[\% \mathrm{C}]+14,2[\% \mathrm{~N}] \\
& +1[\% \mathrm{Cu}]
\end{aligned}
$$

The ferrite potential is given by the following equation:

$$
\mathrm{FP}=5,26 .\left(0,74-\left[\% \mathrm{Ni}^{\prime} / \% \mathrm{Cr}^{\prime}\right]\right)
$$

Some studies have been carried out to understand changes in the heat flux by the peritectic reaction. Singh and Blazek (1974) analyzed the medium heat flux in the mold region by the carbon percentage (up to $1.7 \% \mathrm{C}$ ). For concentrations up to $0.1 \%$, the heat flux decreases, presenting a minimum $\mathrm{C}$ concentration value. Over this concentration rate, the heat flux increases and it is kept constant (concentrations over 0.25\%). Grill and Brimacombe (1976) proposed a mechanism based on phases $\delta \rightarrow \gamma$ reaction to explain the heat flux range. They compared the steel $0.10 \% \mathrm{C}$ to others with larger C concentrations and observed that the former suffers a more intense reaction in the solid state than the latter, with a volume contraction of $0.38 \%$, which reduces the heat flux through the mold wall. Similar results were found by Suzuki et al. (1996).

\section{EXPERIMENTS}

In order to investigate the FP influence on the heat transfer coefficient, two types of steels were selected with different chemical compositions: one with low carbon content and the other with medium carbon content, $0.16 \% \mathrm{C}$ and $0.53 \% \mathrm{C}$ respectively. The chemical composition was analyzed and classified into two categories according to the ferrite potential, such as: type A and type B. Heat transfer coefficients both along the mold length and in three different mold faces were determined from temperatures data obtained by thermocouples strategically positioned in the mold walls. In both cases, a $150 \mathrm{~mm}$ x $150 \mathrm{~mm}$ section cooling copper mold was monitored with type $\mathrm{K}$ thermocouples inserted along the mold height. Heat transfer coefficients were correlated with the steels ferrite potential, which tend to stick or depress from the wall. Experimental data were obtained from an industrial plant by temperatures measured in a mold of the continuous casting machine. Both relevant specifications to the machine and experimental working conditions are shown in Tables 1, 2 and 3. The mold was monitored with 30 thermocouples inserted in the three faces central position of the mold, arranged in the following way: 10 thermocouples in the center of the outer face, 10 thermocouples in the center of the inner face, and 10 thermocouples in the center of the side face.

The thermocouples arrangement along the mold is shown in Figure 3, from the meniscus region (the liquid metal level at the mold top) to $170 \mathrm{~mm}$ from the mold top, up to $31 \mathrm{~mm}$ above the mold exit, which results a total of 10 (ten) strategic points of faces monitoring. Thermocouples were placed at 4.4 $\mathrm{mm}$ from the mold hot face (metal/mold interface). The Tp2 (Thermocouple 2) means the reference of meniscus temperature. 
Table 1. Machine specifications

\begin{tabular}{|l|l|}
\hline Billet section & $150 \times 150 \mathrm{~mm}$ \\
\hline Mold type & Parabolic \\
\hline Mold material & Copper \\
\hline Mold dimensions & $\begin{array}{l}\text { Length: } 801 \mathrm{~mm} \\
\text { Thickness: } 11 \mathrm{~mm}\end{array}$ \\
\hline Machine length & $24 \mathrm{~m}$ \\
\hline
\end{tabular}

Table 2. Monitored heat data in the continuous casting machine for a low-carbon steel.

\begin{tabular}{|l|l|l|l|l|l|}
\hline \multicolumn{5}{|c|}{ Chemical composition (wt \%) } \\
\hline $\mathrm{C}$ & $\mathrm{Si}$ & $\mathrm{Mn}$ & $\mathrm{Mo}$ & $\mathrm{Ni}$ & $\mathrm{Cr}$ \\
\hline 0.16 & 0.22 & 0.65 & 0.21 & 0.09 & 1.1 \\
\hline \multicolumn{5}{|c|}{ Operation data } \\
\hline \multicolumn{5}{|c|}{$1513^{\circ} \mathrm{C}$} \\
\hline Liquidus temperature & $1487^{\circ} \mathrm{C}$ \\
\hline Solidus temperature & $1577^{\circ} \mathrm{C}$ \\
\hline Couring temperature & $2.1 \mathrm{~m} / \mathrm{min}$ \\
\hline Section Speed & $150 \mathrm{x} 150 \mathrm{~mm}$ \\
\hline Ferrite Potential & 0.98 (type A) \\
\hline
\end{tabular}

Table 3. Monitored heat data in the continuous casting machine for a medium-carbon steel.

\begin{tabular}{|l|l|l|l|l|l|}
\hline \multicolumn{5}{|c|}{ Chemical composition (wt \%) } \\
\hline $\mathrm{C}$ & $\mathrm{Si}$ & $\mathrm{Mn}$ & $\mathrm{Mo}$ & $\mathrm{Ni}$ & $\mathrm{Cr}$ \\
\hline 0.53 & 1.3 & 0.67 & 0.04 & 0.11 & 0.66 \\
\hline \multicolumn{5}{|c|}{ Operation data } \\
\hline Liquidus temperature & \multicolumn{3}{|c|}{$1474^{\circ} \mathrm{C}$} \\
\hline Solidus temperature & $1404^{\circ} \mathrm{C}$ \\
\hline Pouring temperature & $1514^{\circ} \mathrm{C}$ \\
\hline Casting Speed & $2.0 \mathrm{~m} / \mathrm{min}$ \\
\hline Section & $150 \times 150 \mathrm{~mm}$ \\
\hline Ferrite Potential & 0.35 (type B) \\
\hline
\end{tabular}

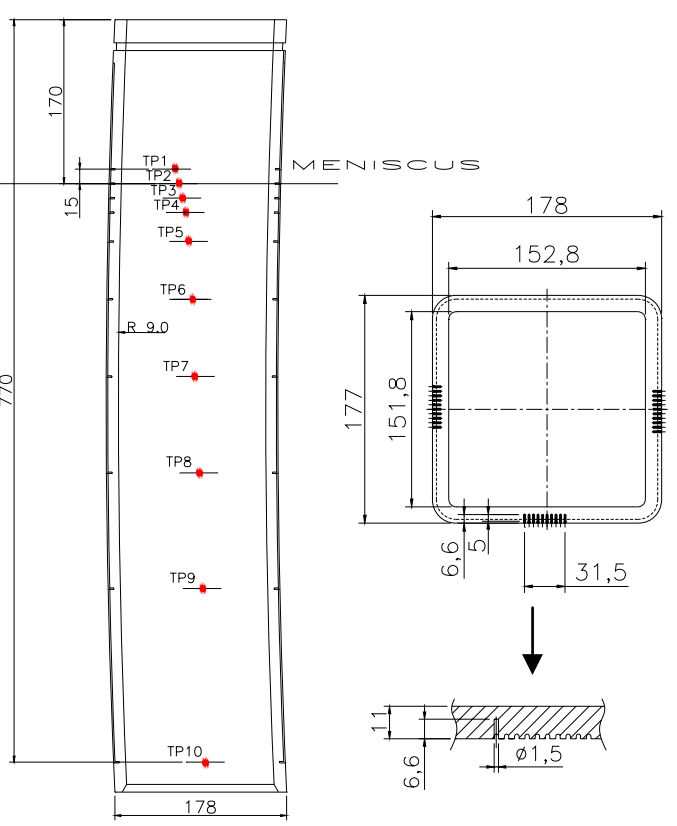

Figure 3. Thermocouples arrangement along the copper mold of the continuous casting machine.
For the macrographic analyses, two blocks of billets were taken from steels employed in this experiment. They were submitted to both a cutting process and a grinding machine with band saws. Figure 4 shows both an image of one of those blocks and a schematic drawing of a cut "slice" for the metallographic procedure. After surface adequacy, the samples were ground on a SiC paper (\#1200), polished on cloth with diamond abrasive and finally etched with $10 \%$ Nital reagent.
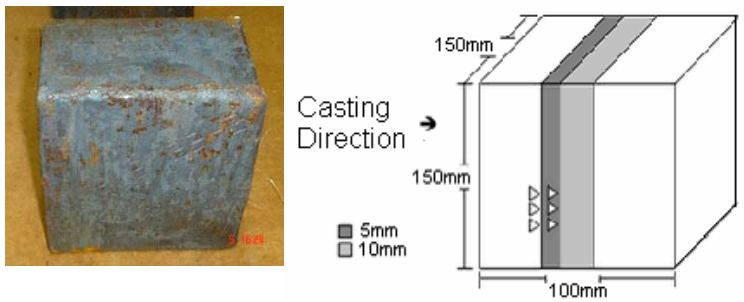

Figure 4. A sample block obtained from the steel billet and a schematic drawing of the sample used for the procedure.

\section{RESULTS AND DISCUSSION}

Figures 5 and 6 show a set of both monitored data of temperatures and results of heat transfer coefficients obtained during solidification for type-A and B steels. Regarding mold walls temperatures, a little difference among monitored temperatures in the mold faces was observed. The inner ray face presents the lowest temperatures in the mold wall due to the mold curvature ray, which reduces the billet contact by the ferrostactic pressure. The side face, however, shows a different behavior for both steels. For typeA steel, between its inner and outer faces, temperatures values are intermediate, whereas for Bsteel, they increase in relation to the outer face. By analyzing temperatures from the meniscus region, a great similarity among maximum temperatures values (approximately $140^{\circ} \mathrm{C}$ ) was observed, in despite of the difference among pouring temperatures (approximately $60^{\circ} \mathrm{C}$ ). For type-B steel, however, the region of maximum temperature extends from the meniscus up to $300 \mathrm{~mm}$ under it.

It is also observed that coefficients achieve their maximum values in the meniscus region due to the best thermal contact between the liquid metal and the mold wall. As these coefficients moves along the mold, they drastically decrease, keeping both a constant feature for type-A steel, and a decreasing variable one for type-B steel. As previously described in Perictectic Reaction, type-A steel has a depression or shrinkage tendency, whereas type-B steel, a sticking or expansion one. This situation has an influence on the behavior of metal/mold heat transfer coefficient along the mold. Therefore, average values around $1500 \mathrm{~W} / \mathrm{m}^{2} . \mathrm{K}$ and 2000 
$\mathrm{W} / \mathrm{m}^{2} . \mathrm{K}$ are obtained for type-A steel and B steel respectively.
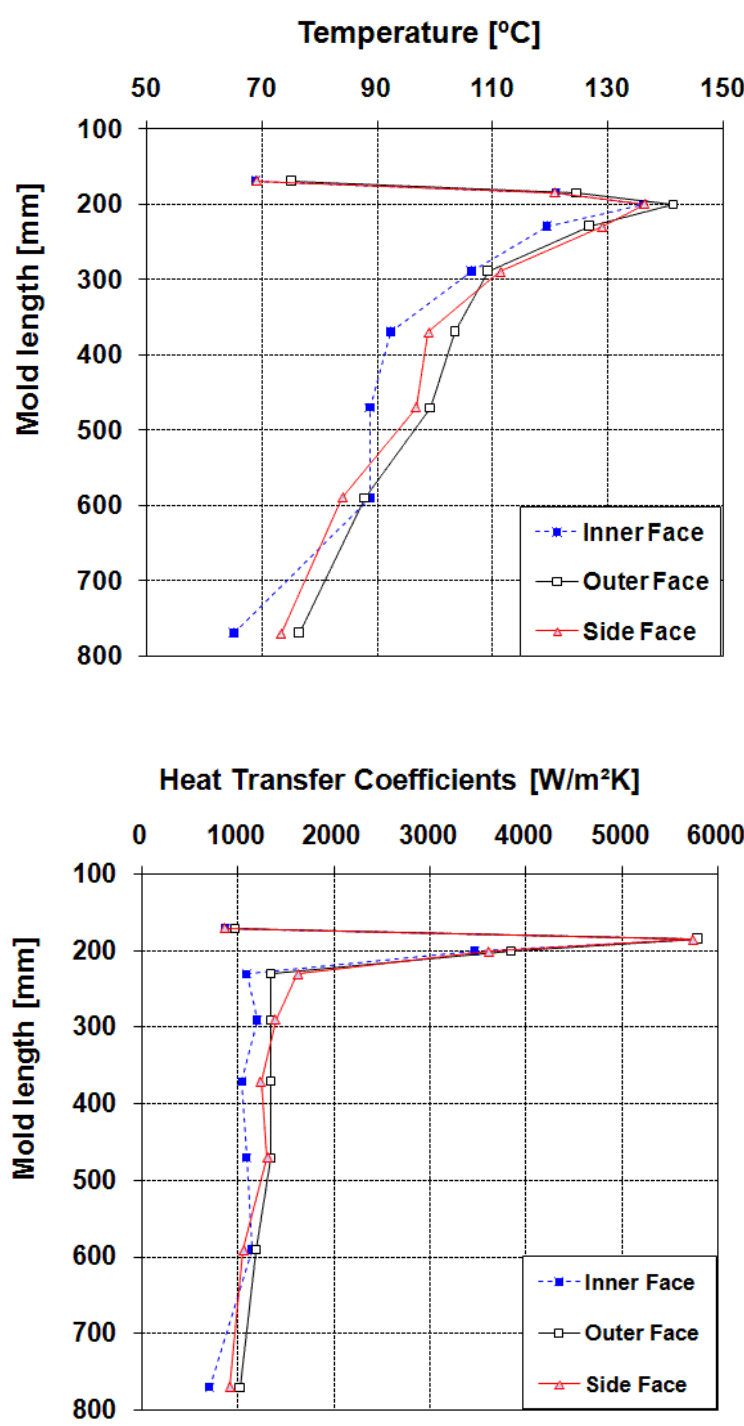

Figure 5. Monitored data of temperatures and results from heat transfer coefficients for A-steel.

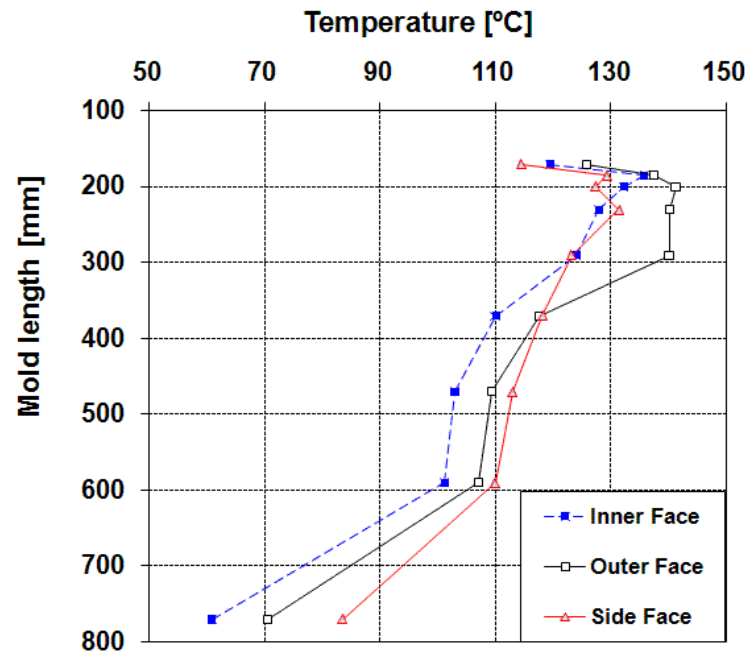

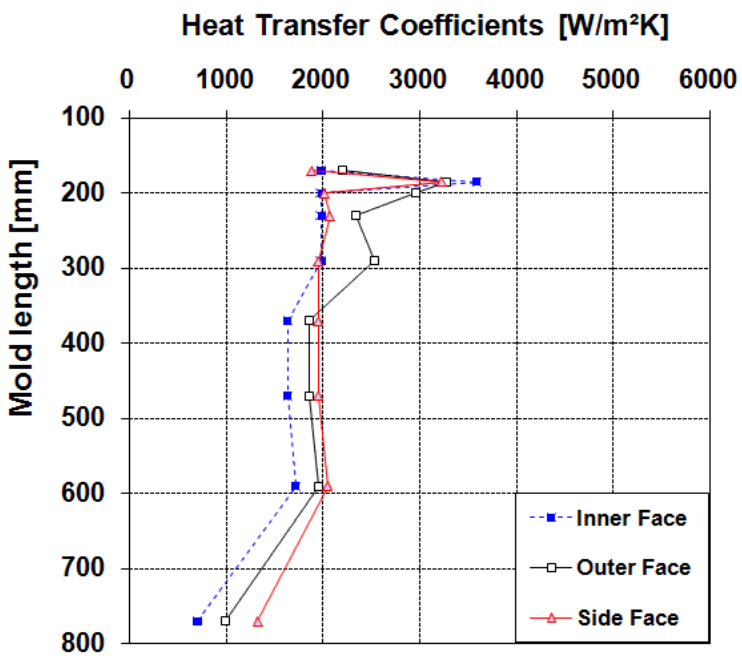

Figure 6. Monitored data of temperatures and results from heat transfer coefficients for B-steel.

Metallographies in Figure 7 show a good correlation with h for each mold face. Furthermore, by means of macrographic images, it can be observed that type-A steel presents a grain structure with both proportional size and orientation among its faces. In other words, the heat extraction rate through the metal/mold interface is homogeneous. For type-B steel however, it was observed that the outer ray face presents the greatest columnar grains, whereas the inner ray face presents the smallest ones. Such observations agree with $\mathrm{h}$ results for each mold face shown in Figures 5 and 6. In type-A steel, a welldefined columnar equiaxed transition can be noted with columnar grains that are perpendicular to the metal/mold interface.

Type A

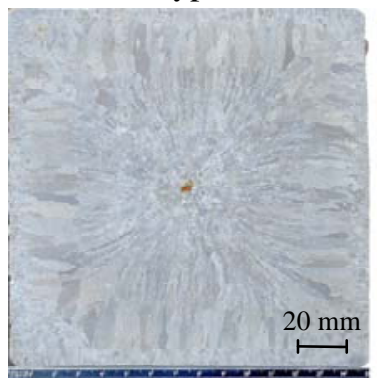

Type B

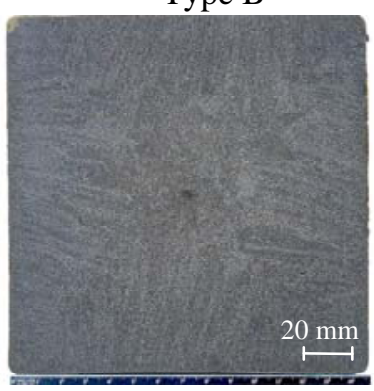

Figure 7. Macroestructures of type-A and B steels.

On the other hand, type-B steel presents an irregular columnar-equiaxed transition, fine columnar grains with a non-perpendicular growth to the metal/mold interface, as well as an equiaxed nucleus dislocated from the center of the billet.

\section{CONCLUSIONS}


The mathematical model was efficient to determine both the ferrite potential and its influence on the heat transfer regime during solidification of steels the along parabolic mold with a square section of $150 \times 150 \mathrm{~mm}$ and $800 \mathrm{~mm}$ of height. Calculated heat transfer coefficients were in accordance with the heat transfer tendency, presenting both high values for the region under the meniscus, where the thermal contact is more effective, and low ones as steel solidification develops.

These coefficients were also important to indicate the difference existent between type-A and $B$ steels heat transfer. The macrographic analysis revealed that internal structures of both types of steels are influenced by the metal/mold heat transfer regime and the liquid-solid interface advance.

\section{ACKNOWLEDGMENTS}

The authors would like to thank CNPq (National Council of Technological and Scientific Development) for the financial support and GERDAU Aços Especiais Piratini for the partnership for studies on the process of solidification by continuous casting.

\section{REFERENCES}

Barcellos, V. K., Fogazzi, W., Ferreira, C. R. F., Santos, C. A., and Spim, J. A., 2006, Desenvolvimento de Rotinas para Determinação e Avaliação dos Coeficientes de Transferência de Calor ao Longo de um Molde durante o Lingotamento Contínuo de Aços, Anais do $61^{\circ}$ Congresso Anual da Associação Brasileira de Metalurgia e Materiais, pp. 995-1005.

Brimacombe, J. K., 1973, Design of Continuous Casting Machines Based on a Heat Flow Analysis, State of the Art Review, Canadian Metallurgical Quartely, Vol. 15, pp. 1-13.

Brimacombe, J. K., Samarasekera, I. V., and Lait, J. E., 1984, Continuous Casting - Heat Flow, Solidification and Crack Formation, Iron \& Steel Society of AIME.

Chandra, S., Brimacombe, J. K., and Samarasekera, I. V., 1993, Mould -Strand Interaction in Continuous Casting of Steel Billets Part 3, Mould Heat Transfer and Taper, Ironmaking \& Steelmaking, Vol. 20, No. 2, pp. 104-112.

Grill, A., and Brimacombe, J. K., 1976, Influence of Carbon Content on Rate of Heat Extraction in the Mould of a Continuous Casting Machine, Ironmaking and Steelmaking, Vol. 3, No.2, pp. 76-79.

Hills, A. W. D., 1969, A Generalized IntegralProfile Method for the Analysis of Unidirectional Heat Flow During Solidification, Transactions of the Minerals, Metals and Materials Society - AIME, Vol. 2445, pp. 1471-1479.
Krishnan, M., and Sharma, D. G. R., 1996, Determination of the Interfacial Heat Transfer Coefficients h in Unidirectional Heat Flow by Beck's Nonlinear Estimation Procedure, International Communications on Heat and Mass Transfer, Vol. 23, No. 12, pp. 203-214.

Lait, J. E., Brimacombe, J. K., and Weinberg, F., 1974, Mathematical Modelling of Heat Flow in the Continuous Casting of Steel, Ironmaking and Steelmaking (Quartely), Vol. 2, pp. 90-97.

Lait, J. E., and Brimacombe, J. K., 1984, Solidification during Continuous Casting of Steel, Continuous Casting - Heat Flow, Solidification and Crack formation, Vol. 2, pp. 171-183.

Mahapatra, R. B., Brimacombe, J. K., Samarasekera, I. V., Walker, N., Paterson, E. A., and Young, J. D., 1991, Mold Behavior and its Influence on Quality in the Continuous Casting of Steel Slabs: Part I, Industrial Trials, Mold Temperature Measurements, and Mathematical Modeling, Metallurgical Transaction B, Vol. 22, pp. 861-874.

Mahapatra, R. B., Brimacombe, J. K., Samarasekera, I. V., Walker, N., Paterson, E. A., and Young, J. D., 1991, Mold Behavior and its Influence on Quality in the Continuous Casting of Steel Slabs: Part II, Mold Heat Transfer, Mold Flux Behavior, Formation of Oscillation Marks, Longitudinal OffCorner Depressions, and Subsurface Cracks, Metallurgical Transaction B, Vol. 22, pp. 875-888.

Matsuura, K., Kudoh, M., and Ohmi, T., 1995, Simulation of Peritectic Reaction during Cooling of Iron-Carbon Alloy, ISIJ International, Vol. 35, No. 6, pp. 624-628.

Mills, K. C., Billany, T. J. H., Normanton, A. S., Walker, B., and Grieveson, P., 1991, Causes of Sticker Breakout During Continuous Casting, Ironmaking and Steelmaking, Vol. 18, No. 4, pp. 253-265.

Santos, C. A., Quaresma, J. M. V., and Garcia, A., 2001, Determination of Transient Interfacial Heat Transfer Coefficients in Chill Mold Castings, Journal of Alloys and Compounds, Vol. 319, No. 1-2, pp. 174-186.

Singh, S. N., and Blazek, K. E., 1974, Heat Transfer and Skin Formation in a Continuous Casting Mold as a Function of Steel Carbon Content, Journal of Metals, pp. 17-27.

Suzuki, M., Yu, C. H., Sato, H., Tsui, Y., Shibata, H., and Emi, T., 1996, Origin of Heat Transfer Anomaly and Solidifying Shell Deformation of Peritectic Steels in Continuous Casting, ISIJ International, Vol. 36, pp. 171-174.

Wolf, M., and Kurz, W., 1981, The Effect of Carbon Content on Solidification of Steel in the Continuous Casting Mold, Metallurgical Transactions B, Vol. 12, pp. 85-93.

Received: April 13, 2008 Revised: May 13, 2008 Accepted: June 13, 2008 